\title{
Characterization of individual airborne particles in Taiyuan City, China
}

\author{
R. K. Xie • H. M. Seip • L. Liu • D. S. Zhang
}

Received: 23 May 2008/Accepted: 27 April 2009 / Published online: 15 May 2009

(C) The Author(s) 2009. This article is published with open access at Springerlink.com

\begin{abstract}
Taiyuan, the capital of Shanxi province, China, is one of the most polluted cities in the world. To characterize the ambient particulate pollution, samples of particulates with aerodynamic diameter less than $10 \mu \mathrm{m}\left(\mathrm{PM}_{10}\right)$ were collected during a 6-day campaign. Individual particles were analyzed by Scanning Electron Microscope with Energy-Dispersive Spectrometer (SEM-EDS) to determine their chemical composition. Meanwhile, photomicrographs were obtained from SEM to aid in particles' source identification. The lumped data from SEM-EDS were subjected to hierarchical cluster analysis (HCA) to sort out particle types chemically. HCA combined with SEM photomicrographs allowed us to identify 20 different particle types, namely (in order of particle frequency), soil/fly ash particles, coal-burning, sulfur-rich, and iron-rich particles, gypsum, syngenite, quartz, cement, silicon sulfide, siliconferro alloy, calcium-rich particles, ferrochromium alloy, ammonium sulfate and chloride, iron-zinc, ammonium chloride, molybdenum-rich, potassium sulfate, dolomite, lead sulfate, and copper-rich particles. Their possible origins and pathways are suggested. The majority of the particles seem to originate from coal combustion, which conforms to Taiyuan's industrial structure.
\end{abstract}

Keywords Air pollution - Individual particle analysis . Hierarchical cluster analysis $\cdot$ PM10 · SEM-EDS

\footnotetext{
R. K. Xie $(\varangle) \cdot$ H. M. Seip $\cdot$ D. S. Zhang

Department of Chemistry, University of Oslo,

P.B. 1033, Oslo, Norway

e-mail: ruikaixi@kjemi.uio.no

L. Liu

Norwegian Institute for Air Research,

P.B. 100, Oslo, Norway
}

\section{Introduction}

Airborne particulate matter is the sum of all solid and liquid particles suspended in air. This complex mixture includes both organic and inorganic particles with varying size, composition, and origins. Particulate matter frequently contains toxic components and they influence global climate and visibility of atmosphere.

Information about the size, morphology and composition of $\mathrm{PM}_{10}$ in the atmosphere can provide clues about its source. For example, coarse particles that contain distinctive compounds, such as silica, iron, calcium, potassium, sodium and magnesium, are likely from wind-blown soil, but finer particles containing elemental and organic carbon are likely from combustion sources. The size, morphology, and composition of $\mathrm{PM}_{10}$ can also provide clues about process performance. For example, for a spherical, fine particle containing mainly silicon and aluminum, coal combustion may be a likely source (Xie et al. 2005). Characterizing $\mathrm{PM}_{10}$ can also help to understand potential health effects of airborne particles (HEI, Health Effects Institute 2002).

SEM-EDS can determine particle size, shape, and elemental composition of particles. Photomicrographs of individual particles can be acquired to provide particle morphology data. Statistical methods can be used to sort particles into distinct particle classes based on chemical characteristics to aid in source identification. SEM-EDS and similar techniques, such as electron microprobe have been used by many aerosol researchers in identifying different particles and linking them to possible sources (Anderson et al. 1988; Van Born and Adams 1988; Van Malderen et al. 1996). Detailed knowledge of the compositions of individual particles from the aerosol can lead to recognition of previously unknown sources (Post and Buseck 1984). 
Taiyuan is a center for energy production and chemical and metallurgical industries. The production of raw coal reached about 34 million tons in 2003, which was $2.5 \%$ of the total raw coal production of China (Shanxi Statistics 2004). The annual coal consumption is around 25 million tons, of which 9.6 million tons are for energy use, accounting for $95 \%$ of the total energy production (Environmental Monitoring Center of Taiyuan 2004). Main industrial activities include production of raw coal, coke, electricity, steel, chemical fertilizers and building materials, some of which are energy and/or pollution intensive. Taiyuan is one of the most polluted cities in the world (World Bank 1997; Mestl et al. 2005). Several studies have shown that the pollution levels in Taiyuan are detrimental to human health (Zhang and Zhang 2003; Zhao 2003; Hu et al. 2004). Many point- and area sources may contribute to the build-up of airborne particulates in Taiyuan, but their relative contribution to a given area will vary depending on their locations, meteorological conditions, etc. This study focuses on chemical characterization of the particulate matters and attempts to identify possible sources.

\section{Site descriptions}

Taiyuan covers an area of $1,500 \mathrm{~km}^{2}$ and has a population of 2.67 million. It is surrounded by mountains to the east, west, and north. Taiyuan has a marked continental monsoonal climate. North-westerly and northerly winds prevail in winter, while southerly and south-easterly winds reign in summer. Average annual precipitation is $456 \mathrm{~mm}$ and most of the rain falls in the warm season. Air quality is affected by the frequent occurrence of inversion layers. In winter, the frequency is $80 \%$, with an average inversion depth of $490 \mathrm{~m}$; while in summer it is $60 \%$, with a thinner inversion of $247 \mathrm{~m}$ (Environmental Monitoring Center of Taiyuan 2001).

Taiyuan is a heavily industrialized area in central China that still greatly relies on uncontrolled coal combustion. This reliance, combined with unfavorable dispersion conditions has resulted in extremely high ambient $\mathrm{SO}_{2}$ and particulate levels in the city. The 5-year (1996-2000) average $\mathrm{SO}_{2}$ and TSP (total suspended particles) concentrations are 241 and $467 \mu \mathrm{g} / \mathrm{m}^{3}$, respectively, which are 4.0 and 2.3 times the second level values of the National Ambient Air Quality standards (Environmental Monitoring Center of Taiyuan 2001).

The sampling site was at the campus of Taiyuan University of Science and Technology (see Fig. 1) on the roof of a four-story office building. Some of the major point and area sources are shown in Fig. 1. As indicated on the map, Power plant $1^{\#}$, Power plant $2^{\#}$, and the Iron and \& Steel Group Company are the largest industrial polluters in
Taiyuan representing $50 \%$ of industrial TSP emissions (Mestl and Fang 2003). Xishan Coal and Power Group Company Ltd and Taiyuan Heavy Machinery Making Group Company Ltd are also important polluters. There is a cement plant in the vicinity of the sampling site and another two to the northwest. There are areas where households still use raw coal or briquettes for heating and cooking, the most important one is shown in Fig. 1, although the share of the households using raw coal or briquettes is declining. Due to low emission heights, these sources are likely to have large effects on the pollution concentrations close to the surface. Many intermediate and small particulate emitting sources are omitted for clarity purpose.

\section{Experimental}

\section{Sampling}

A medium flow (100 $1 \mathrm{~min}^{-1}$ ) sampler (Wuhan Tianhong Intelligent Instrument Plant) was used with an impactor cutoff of $10 \mu \mathrm{m}$ (aerodynamic diameter). Six samples were collected. Particles $\left(\mathrm{PM}_{10}\right)$ were sampled on $90-\mathrm{mm}$ diameter, 1- $\mu$ m-pore-size Fluoropore ${ }^{\circledR}$ (PTFE) membrane filters. Prior to setting the sampling program, a TSI DustTrak $^{\mathrm{TM}} 8520$ Aerosol Particulate Monitor was used for a quick spot check of the $\mathrm{PM}_{10}$ concentration. Either 5 or $10 \mathrm{~min} / \mathrm{h}$ was adopted depending on the measured $\mathrm{PM}_{10}$ concentration. The sampling lasted for $24 \mathrm{~h}$, and accordingly the sampling duration for each day was 2 or $4 \mathrm{~h}$. The program was set as such that sufficient particle were distributed on the filter surface while undesirable overloading was avoided. Sampling dates, durations, and meteorological data are shown in Table 1.

\section{SEM-EDS analysis}

Single-particle analysis was performed using a Hitachi S4300SE-Shotky Field Emitter Scan Electron Microscope. This instrument is equipped with an Oxford 6853 energydispersive spectroscopic detector, and is automated by Oxford Instruments INCA Energy and Feature software. The detailed description of the analysis procedures can be found elsewhere (Xie et al. 2005). Essentially, during analysis, the electron beam scans over a preset area. When the backscattered electron intensity of the particle contour exceeds a predefined threshold value, the object is considered detected. An X-ray spectrum from the center of the particle can be accumulated and subsequently the spectrum is processed automatically with a built-in XPP correction procedure. Elements lighter than $\mathrm{Na}$ are not determined with sufficient accuracy and have been exclud- 
Fig. 1 Sampling site and some important PM sources

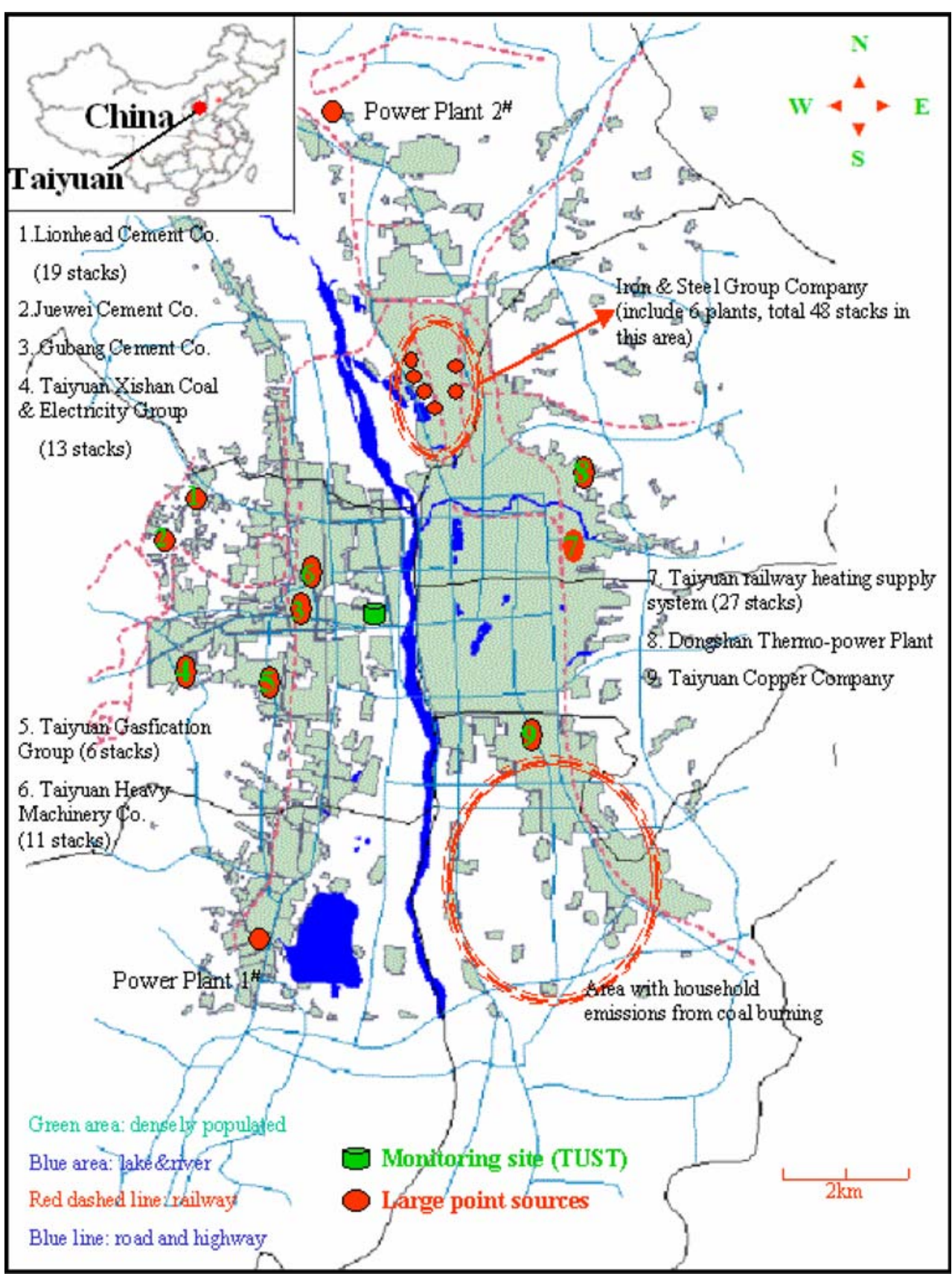

Table 1 Sampling dates, durations and meteorological conditions

\begin{tabular}{llllll}
\hline Sample & Sampling date & Sampling duration & Average Temperature $\left({ }^{\circ} \mathrm{C}\right)$ & Episode(s) & Precipitation $(\mathrm{mm})$ \\
\hline 1 & $14,07,2003$ & $4 \mathrm{~h}$ & 18.0 & Cloudy, Light fog & 0 \\
2 & $15,07,2003$ & $4 \mathrm{~h}$ & 24.8 & Sunny & 0 \\
3 & $16,07,2003$ & $2 \mathrm{~h}$ & 21.6 & Light fog & 0.1 \\
4 & $17,07,2003$ & $2 \mathrm{~h}$ & 19.3 & Light fog, Light rain & 0.7 \\
5 & $18,07,2003$ & $4 \mathrm{~h}$ & 18.7 & Light rain & 6.4 \\
6 & $19,07,2003$ & $2 \mathrm{~h}$ & 24.0 & Light fog & 0.1 \\
\hline
\end{tabular}


ed. The equivalent circular diameter (ECD), defined as the diameter of a circle with the same area as the projected particle, and the shape factor, defined as the ratio of the square of the perimeter to $4 \pi$ times the area, are also measured. About 400 particles were automatically analyzed for each sample. The threshold for diameter was $0.19 \mu \mathrm{m}$. The X-ray spectrum was accumulated for $15 \mathrm{~s}$ with a beam current of $0.3 \mathrm{nA}$ and acceleration voltage of $15 \mathrm{KV}$. The relative percentage of the elements was normalized so that the sum of the included elements is 100. The analysis' precision and accuracy were checked by analyzing laboratory prepared fine particles of $\mathrm{NaCl}$ and $\mathrm{KCl}$. The $95 \%$ confidence interval of the atomic fraction for $\mathrm{Na}$ in $\mathrm{NaCl}$ and $\mathrm{K}$ in $\mathrm{KCl}$ were 49.3-51.9 and 47.4-48.2.

\section{Data processing}

The 6-day samples, with a total number of 2,329 particles, were considered as a lumped sample. With such a relatively large data set, some form of data reduction is needed. Hierarchical cluster analysis (HCA) can greatly reduce the data while retaining the most important information embedded in the raw data.

The purpose of cluster analysis is to sort particles into groups, or clusters, so that the degree of association is strong between members of the same cluster and weak between members of different clusters. We use hierarchical cluster analysis to identify the particle types according to their chemical composition. The MINITAB statistics software is applied (http://www.minitab.com/). The squared Euclidean distance is used to measure the similarity of the particles. Each particle $(i)$ is represented by an object vector with the components $\left(X_{i}, 1, X_{i}, 2, \ldots \ldots X_{i, n}\right)$ representing the weight percentage of the $n$ chemical elements. The squared Euclidean distance of particle $i$ and particle $j$ is defined as:

$d_{i j}^{2}=\sum_{k=1}^{n}\left(X_{i k}-X_{j k}\right)^{2}$

where the index $k$ represents the considered element. Ward's method (Van Born and Adams 1988) was applied on the relative percentage of the elements based on the covariance matrix.

A major problem with this method is to obtain the right number of clusters to reflect the "true" particle types. A toolow number will lead to clusters with particles belonging to different groups, while a too high number may cause split of inherently "identical" particles. This can be overcome by setting a "cutoff" to the dendrogram based on Akaike's criterion used by Bondarenko et al. (1994) on Lake Baikal aerosol particles. Yet we found it satisfactory to perform a stepwise hierarchical cluster analysis and judge the best number of clusters by comparing intra- and inter-cluster "distances" and the possibility of interpreting the cluster pattern in terms of sources.

\section{Results and discussion}

The HCA applied to 2329 particles (17 variables) yielded 20 different particle types as presented in Table 2. This analysis was done by a stepwise approach, and the number of the particle types was based on the inter-cluster distances and chemical explainability. Since important light elements, such as $\mathrm{C}, \mathrm{N}$, and $\mathrm{O}$, were excluded in the analyses, some important particle types, such as ammonium nitrate, soot, organic carbon and particles of biological origin, could not be identified. The weight percentages given in Table 2 are based only on the 17 elements determined. The relative abundance of particle types in each sample is also listed.

Soil/fly ash particles Soil particles (Fig. 2a) and fly ash particles (Fig. 2b), dominated by $\mathrm{Si}$ and $\mathrm{Al}$, cannot be distinguished by their chemistry, and are put in the same cluster by the HCA. Together, these two particle types constitute the largest cluster. Generally, the spherical particles are derived from fluid melts due to hightemperature combustion (Xie et al. 2005 and references therein). The shape factor close to unity indicating a spherical shape may suggest that the large majority of these particles are formed at high temperatures and therefore are fly ash rather than soil. This interpretation is consistent with the prevailing weather conditions at the time since immediately before and during part of the sampling period it was raining, reducing the amounts of soil particles whirled into the air by wind or resuspended by traffic.

Coal-burning particles Coal-burning particles are produced in coal-fired power stations, boilers, kilns (e.g., for making building materials) and by domestic cooking appliances. This particle type mainly contains the elements $\mathrm{Si}, \mathrm{Al}, \mathrm{S}$, $\mathrm{Ca}$, and $\mathrm{Fe}$ (Fig. 2c). Raw coal contains various amounts of ash, mainly kaolinite, quartz, siderite, calcite, dolomite, and sulfur, mainly as organic sulfur, pyrite $\left(\mathrm{FeS}_{2} \cdot n \mathrm{H}_{2} \mathrm{O}\right)$ and sulfate (mainly $\mathrm{CaSO}_{4}$ ). When coal is burned at high temperature, all major minerals in coal will undergo extensive coalescence forming gypsum/Al-silicates (Xie et al. 2005, and references therein). This type of particles accounts for $16.3 \%$ of the total numbers of the particles analyzed (see Table 2), reflecting the intensity of coal consumption in Taiyuan area.

Sulfur-rich particles This particle type is characterized by high amounts of sulfur, ranging from $51 \%$ to $100 \%$. Particles with close to $100 \%$ of sulfur likely represent 


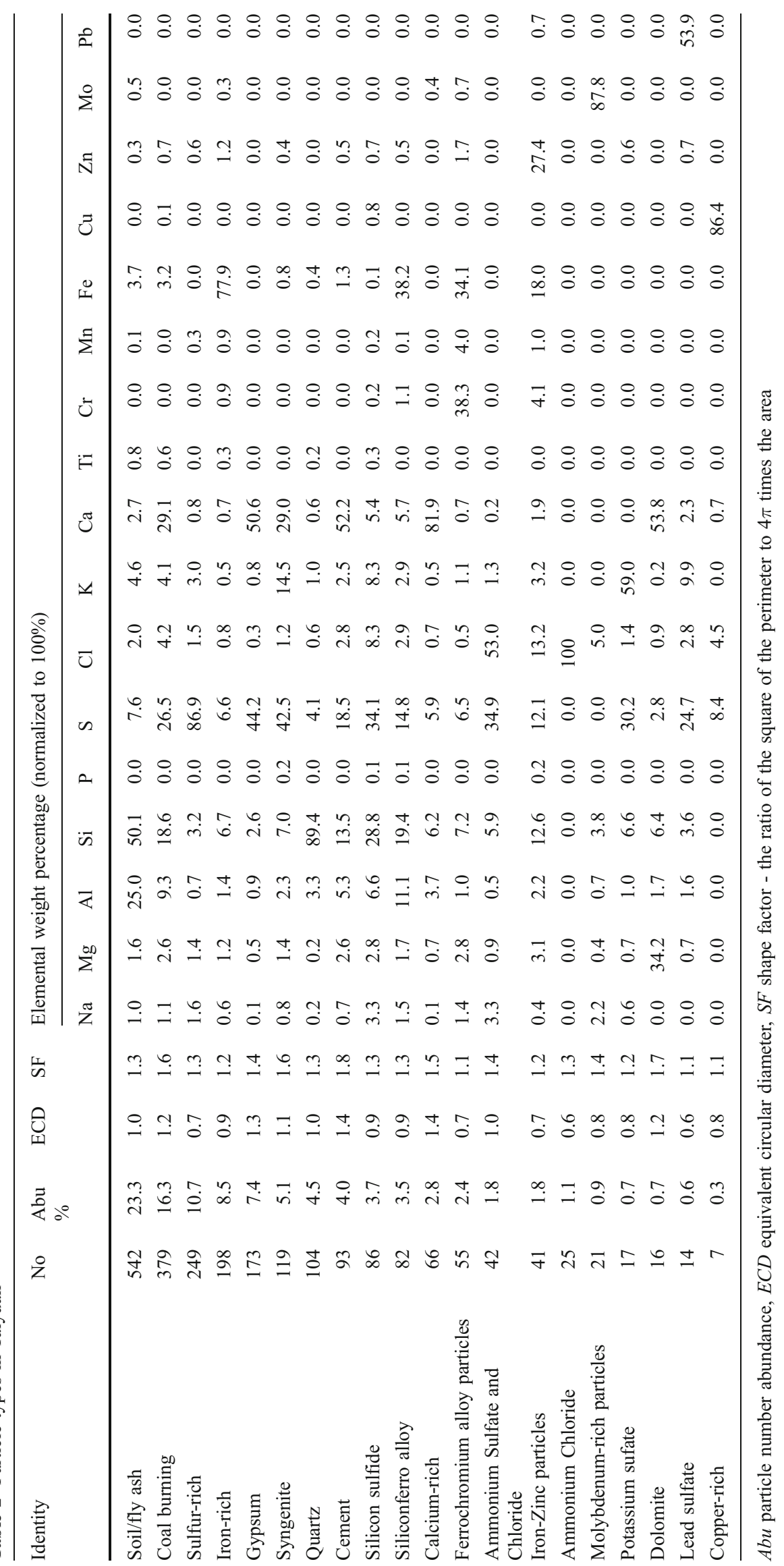



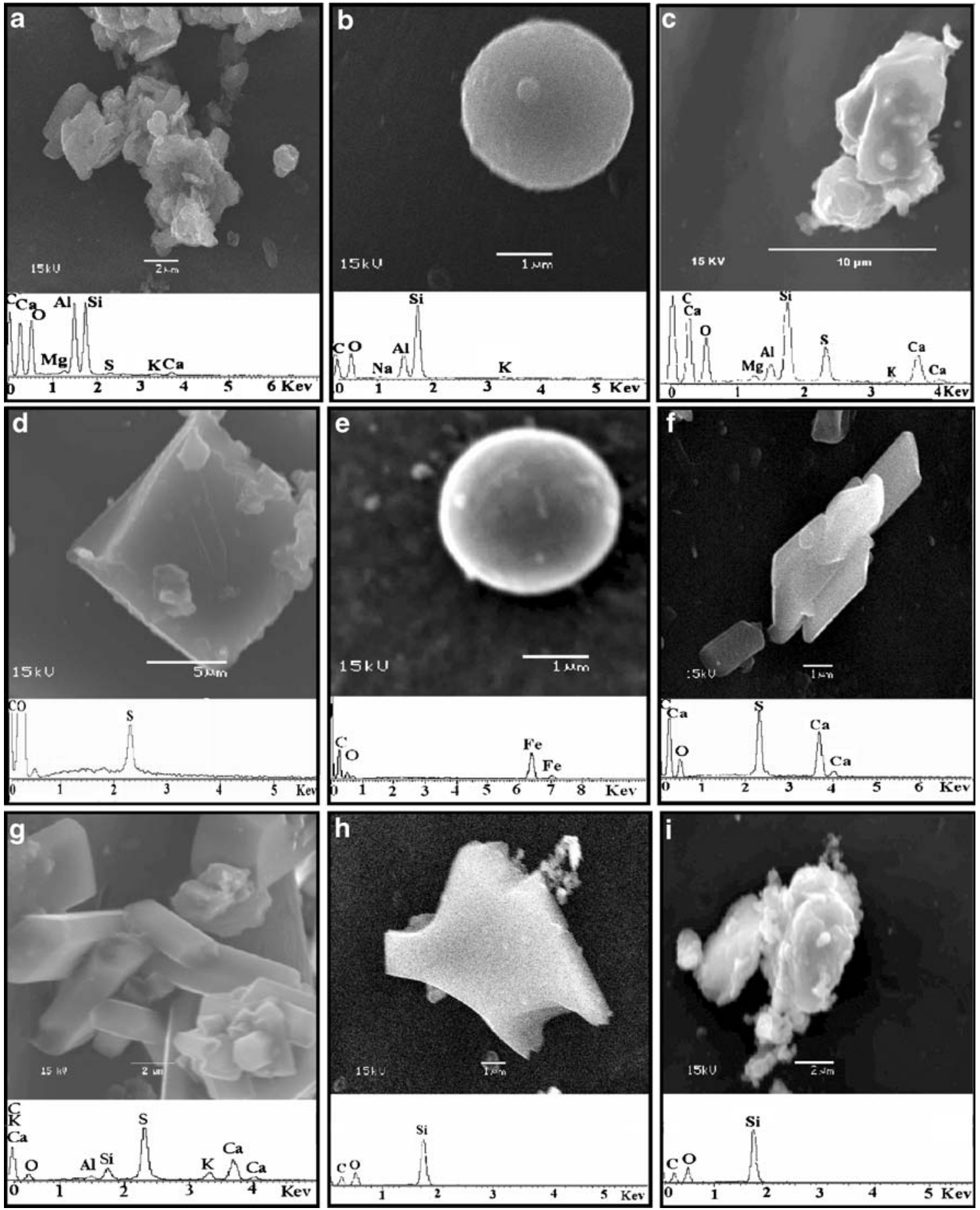

Fig. 2 SEM photomicrographs and EDS spectra of particles (sampled for $24 \mathrm{~h}$ ). Some overlapping or aggregation of particles is seen. a Soil particles; b a fly ash particle; c aggregated coal burning particles; $\mathbf{d}$ a sulfur-rich particle, possibly an ammonium sulfate particle; e an iron particle; f gypsum particles; $\mathbf{g}$ synegnite particles; $\mathbf{h}$ a natural quartz

secondary aerosols resulting from gas-to-particle conversion of sulfur compounds, in the forms of sulfuric acid, and/ or ammonium sulfate and bisulfate. Figure $2 \mathrm{~d}$ is a typical ammonium sulfate particle. Ammonia can be emitted from particle; i quartz particle agglomerate from coal combustion; $\mathbf{j}$ cement particle aggregates; $\mathbf{k} \mathrm{CaCO}_{3}$ particles; $\mathbf{I}$ a hydrated lime particle; $\mathbf{m}$ a ferrochromium alloy particles attached by some other small particles; (n) dolomite aggregate

fertilizer manufacturing plants and agricultural activities. But, in Taiyuan, coal combustion, coal gasification, and coke making may be more important sources. For every ton of coke produced, $0.1 \mathrm{~kg}$ of ammonia may be released to 

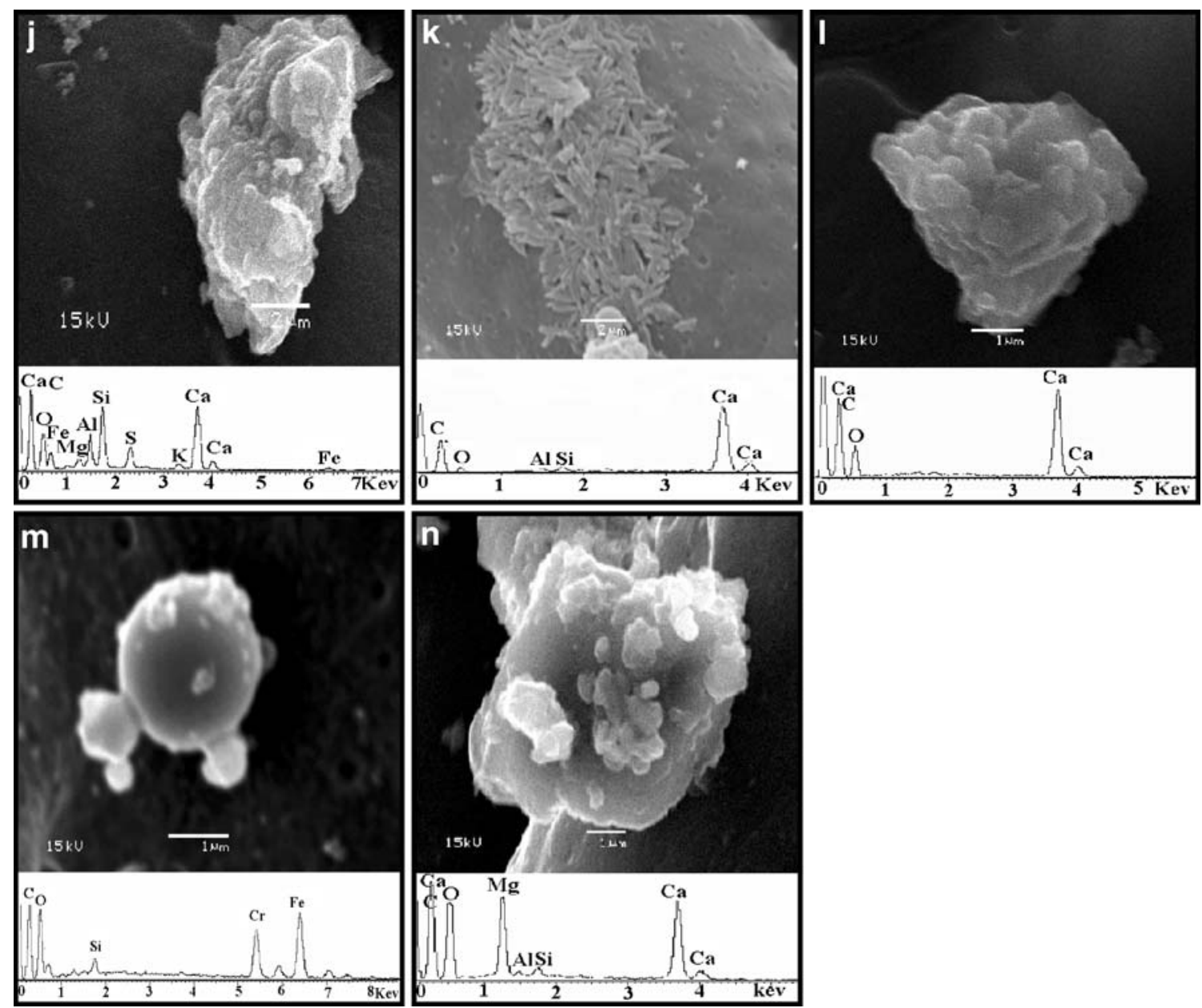

Fig. 2 (continued)

the atmosphere if there is no vapor recovery system (World Bank 1998). Sulfur dioxide, precursor of sulfate, is mostly from coal combustion.

Iron-rich particles Iron can originate from both natural and anthropogenic origins, e.g., from soil, mining, and ferrous metallurgic industry. It seems reasonable that some of the particles originated from the Iron \& Steel Group Company, which is situated north of the city (Fig. 1). But contribution from coal combustion is also possible; particles can be formed by oxidation of pyrite $\left(\mathrm{FeS}_{2}\right)$ in coal. The iron-rich particle in Fig. 2e was a product of a high-temperature process and is either from the steel industry or from coal combustion.

Gypsum Particles in this cluster, containing mainly $\mathrm{S}$ and $\mathrm{Ca}$ in nearly equal atomic amounts, are most likely gypsum with some impurities, like silicates (Fig. 2f). The presence of gypsum particles is common and can be traced to many sources. In Taiyuan, the largest fraction is presumably from coal combustion. During coal combustion, a part of the total sulfur is retained as a result of reactions between feed or indigenous limestone and sulfur.

Syngenite This particle type contains mainly S, K, and Ca with some minor amounts of other elements (Fig. $2 \mathrm{~g}$ ). It was first reported in urban atmosphere in our previous study (Xie et al. 2005), in which we suggested that coal combustion and/or the cement industry were possible sources.

Quartz particles Particles in this cluster contain mainly silicon (nearly $90 \%$ on average) and are classified as quartz $\left(\mathrm{SiO}_{2}\right)$. Quartz particles may be in natural form (Fig. 2h), originating from soil suspension or from industries where quartz is utilized. Another pathway is from coal combustion (Fig. 2i). Silicon, the most abundant element in coal ash, exists in coal both as quartz and in many other compounds 
such as clays and feldspars. $\mathrm{SiO}_{2}$ is formed by reduction of silicon-containing compounds at high temperature followed by evaporation, oxidation, and nucleation processes (Xie et al. 2005).

Cement particles These particles are characterized by high content of $\mathrm{Ca}$, moderate amounts of $\mathrm{S}$ and $\mathrm{Si}$, and minor amounts of $\mathrm{Mg}, \mathrm{Al}, \mathrm{Cl}, \mathrm{K}$, and Fe (Fig. 2j). They are most probably emitted during cement manufacturing, notably the cement installations marked in Fig. 1.

Silicon sulfide particles This particle type resembles silicon sulfide stoichiometrically. As far as we know, its presence in ambient air has never been reported. This is another form of coal combustion product (so called CCP). The formation mechanism was reported by Nagelberg (1985), who concluded that, in the presence of carbon, the fuel-borne sulfur can readily react with $\mathrm{SiO}_{2}$ to form silicon sulfide vapor.

Silicoferro alloy particles In this particle type, iron and silicon are found in nearly equal atomic amounts, with somewhat less sulfur and aluminum. These particles are most probably from metallurgical industry, where siliconiron alloy is produced.

Calcium-rich particles This particle type is strongly dominated by $\mathrm{Ca}$ with some contributions of $\mathrm{S}, \mathrm{Si}$, and $\mathrm{Al}$. Some of these particles are limestone $\left(\mathrm{CaCO}_{3}\right)$ with some impurities (Fig. 2k). Limestone particles are generated through its application in many areas, e.g. as building material, in cement manufacturing, and in metallurgic industry. Some are hydrated lime from limekilns (Fig. 21), in which lime is produced for application in metallurgical industry and building construction.

Ferrochromium alloy particles High contents of chromium and iron characterize this particle type (Fig. 2m). The near unity shape factor indicates that they originate from high-temperature processes. They may stem from the iron and steel works in the northeast. Ferrochromium alloy is used to manufacture high-grade stainless alloy steel.

Ammonium chloride/sulfate Individual particle chemistry inspection shows that particles in this cluster actually contain both chloride and sulfate, presumably associated with ammonium, and that the cluster is not a mixture of two different particle types misclassified by the statistical approach. The origin of these particles is most likely coal combustion and coke making just as sulfur-rich particles mentioned above and ammonium chloride to be discussed (see below).
Iron-zinc particles These particles contain mainly $\mathrm{Zn}$ and $\mathrm{Fe}$, but also on average $12-13 \%$ of each of the elements $\mathrm{Si}$, $\mathrm{S}$, and $\mathrm{Cl}$. They are most likely of the same origin as siliconferro alloy particles, i.e., from metallurgical industry.

Ammonium chloride Ammonium chloride is thought to be formed by reaction between gaseous ammonia and hydrogen chloride. Hydrogen chloride is most likely from coal combustion and the coke industry.

Molybdenum-rich particles Molybdenum is primarily used as an alloying element in steel, cast iron, and nonferrous metals.

Potassium sulfate The formation mechanism of potassium sulfate may be analogous to that of gypsum. Generally, the potassium content in raw coal is much lower than that of calcium, and it is associated with aluminosilicates and feldspars, which are less likely to absorb sulfur. This may explain its lower abundance relative to calcium sulfate (gypsum).

Dolomite Dolomite is a common mineral in Taiyuan (Fig. 2n). Airborne dolomite particles can be both natural and from industrial process. Dolomite is applied in many fields; it may also be emitted during cement manufacturing.

Lead sulfate The source is not likely to be leaded petrol since the particles contain little or no $\mathrm{Cl}$ and $\mathrm{Br}$. This is consistent with lead in petrol being phased out in China. In Taiyuan, the lead-containing particles are most likely from metallurgical smelters, heavy machinery manufacturing, and coal combustion.

Copper-rich particles This particle type contains mainly copper, but also some $\mathrm{S}$ and $\mathrm{Cl}$. The shape factor is near unity, consistent with the high temperature under which copper is melted and particles are emitted. Quite possibly, the particles originate from a copper smelter $6 \mathrm{~km}$ to the southeast.

Our results (Table 2) show that quite a large number of particles are from coal combustion: fly ash particles (23.3\%, assuming the number of soil particles to be negligible as discussed previously), coal-burning particles (16.3\%), sulfur-rich particles $(10.7 \%)$, gypsum particles (7.4\%), syngenite particles (5.1\%), and silicon sulfide particles $(3.7 \%)$. Our samples were collected in summer, when coal consumption is not at its peak. An even larger contribution of particles from coal combustion is expected in winter when coal consumed for space heating aggravates the burden of particulate pollution (Environmental Monitoring Center of Taiyuan 2004). The nature of the particulate matter pollution in Taiyuan is also corroborated by our bulk sample 
analysis by using Inductively Coupled Plasma Atomic Emission Spectrometry (ICP-AES) and Inductively Coupled Plasma Mass Spectrometry (ICP-MS), where the concentrations of trace elements such as arsenic and selenium could only be explained by assuming coal combustion to be an important source (Xie et al. 2006).

The composition of particulates at a given site is governed by many factors such as location and emission height of nearby sources, topography, meteorological conditions etc. Mestl et al. (2005) modeled pollutant dispersion in Taiyuan and showed that low level emission sources were responsible for most of the particulate pollution close to the ground, and thus for most of the health damage.

Normally, trace heavy metals in airborne particles cannot be detected by SEM-EDS due to technique limitation. But in Taiyuan, several heavy metals, such as chromium, zinc, molybdenum, lead, and copper were present as major elements in some particle types. The presence of zinc, lead, and copper (chromium and molybdenum were not analyzed) was also confirmed by their elevated concentrations and high enrichment factors in our bulk sample analyses (Xie et al. 2006).

\section{Conclusions}

SEM-EDS analysis is an excellent method for characterizing airborne particulate matter, especially for individual particles. Combined with SEM photomicrographs and HCA, SEM-EDS analysis can identify the major particle sources and formation processes. The large variety of particle types reveals the complexity of particulate pollution and reflects the multiple industrial activities in Taiyuan. Coal combustion is the main source of particles in Taiyuan air, as evidenced by the abundance of the characteristic coal-burning-related particles. This conclusion is consistent with the industrial structure and the large use of coal, as well as with the bulk sample analyses by ICP-AES/MS. Clearly, in Taiyuan the reduction of coal combustion emissions will have large beneficial effects on residents' health. The uncovered particle sources and formation processes of the particles in this study can contribute to a better understanding of the particulate pollution nature and a clearer strategy for pollution abatement.

Acknowledgment Advice and sampling assistance from Professor Jinghua Fang and Master Student Hongge Li at Taiyuan University of Science and Technology are greatly appreciated.

Open Access This article is distributed under the terms of the Creative Commons Attribution Noncommercial License which permits any noncommercial use, distribution, and reproduction in any medium, provided the original author(s) and source are credited.

\section{References}

Anderson JR, Aggett J, Buseck PR, Germani MS, Shattuck TW (1988) Chemistry of individual particles from Chandler, Arizona, an arid urban environment. Environ Sci Technol 22:811-818. doi:10.1021/es00172a011

Bondarenko I, Van Malderen H, Treiger B, Van Espen P, Van Grieken R (1994) Hierarchical cluster analysis with stopping rules built on Akaike's information criterion for aerosol particle classification based on electron probe X-ray microanalysis. Chemom Intell Lab Syst 22:87-95. doi:10.1016/0169-7439(93) E0052-6

Environmental Monitoring Center of Taiyuan (2001) Environmental Quality Report for Taiyuan, 1996-2000. Taiyuan, Shanxi, China

Environmental Monitoring Center of Taiyuan (2004) Environmental Quality Report for Taiyuan, 2003. Taiyuan, Shanxi, China

HEI (Health Effects Institute) (2002) Understanding the health effects of components of particulate matter mix: progress and next steps, HEI perspectives.

Hu EB, Wu QH, Wang H, Ji SW, Xin CT (2004) Study on the environment risk through inhalation pathway in Taiyuan City. Huanjing Kexue Xuebao 24(1):116-120 In Chinese, with English abstract

Mestl HES, Fang JH (2003) Air quality estimates in Taiyuan, Shanxi Province, China-application of a multiple-source dispersion model. CICERO Report, Oslo, Norway

Mestl HES, Aunan K, Fang JH, Seip HM, Skjelvik JM, Vennemo H (2005) Cleaner production as climate investment-integrated assessment in Taiyuan City, China. J Clearner Prod 13:57-70. doi:10.1016/j.jclepro.2003.08.005

Nagelberg AS (1985) Vaporization of silica under coal combustion conditions. Proc- Int Conf Coal Sci 385-8. Pergamon, Sydney, Australia.

Post JE, Buseck PR (1984) Characterization of individual particles in the Phoenix urban aerosol, using electron beam instruments. Environ Sci Technol 18:35-42. doi:10.1021/es00119a009

Shanxi Statistics Bureau (2004) Shanxi Statistical Yearly book, 2003, China Statistics Press.

Van Born WA, Adams FC (1988) Cluster analysis of electron microprobe analysis data of individual particles for source apportionment of air particulate matter. Atmos Environ 22:229-237

Van Malderen H, Van Grieken R, Khodzher T, Obolkin V, Potemkin V (1996) Composition of individual aerosol particles above Lake Baikal, Siberia. Atmos Environ 30:1453-1465. doi:10.1016/ 1352-2310(95)00430-0

World Bank (1997) China 2020: Development challenges in the new century, Washington D. C.

World Bank Group (1998) Pollution, prevention and abatement handbook 1998: toward cleaner production 286-290, Washington D. C.

Xie RK, Seip HM, Leinum JR, Winje T, Xiao JS (2005) Chemical characterization of individual particles $\left(\mathrm{PM}_{10}\right)$ from ambient air in Guiyang City, China. Sci Total Environ 343:261-272. doi:10.1016/j.scitotenv.2004.10.012

Xie RK, Seip HM, Wibetoe G, Nori S, Mcleod CW (2006) Heavy coal combustion as the dominant source of particulate pollution in Taiyuan, China, corroborated by high concentrations of arsenic and selenium in $\mathrm{PM}_{10}$. Sci Total Environ 370:409-415. doi:10.1016/j.scitotenv.2006.07.004

Zhang YP, Zhang XP (2003) Association between air pollution and hospital daily mortality in Taiyuan. Huanjing Yu Zhiye Yixue 20:198-202 In Chinese, with English abstract

Zhao BX (2003) Study on the effect of $\mathrm{PM}_{10}$ and $\mathrm{SO}_{2}$ air pollution on children's pulmonary function in Taiyuan City, China. Huanjing Yu Zhiye Yixue 20:203-206 In Chinese, with English abstract 